\title{
How much septal-lateral mitral annular reduction do you get with new ischemic/functional mitral regurgitation annuloplasty rings?
}

\author{
Wolfgang Bothe, MD, ${ }^{a}$ Julia C. Swanson, $\mathrm{MD},{ }^{\mathrm{a}}$ Neil B. Ingels, $\mathrm{PhD},{ }^{\mathrm{a}, \mathrm{b}}$ and D. Craig Miller, MD
}

Objective: Disproportionate reduction of the mitral septal-lateral annular dimension is the goal in the surgical treatment of ischemic or functional mitral regurgitation and avoids the need for ring "downsizing." How much the new annuloplasty rings designed for patients with ischemic/functional mitral regurgitation reduce annular septal-lateral dimension, however, is proprietary information and debated.

Methods: Outer and inner septal-lateral and commissure-commissure diameters of all available sizes of Edwards GeoForm, Edwards IMR ETlogix (both Edwards Lifesciences, Irvine, Calif), St Jude Medical Rigid Saddle Annuloplasty Ring (St Jude Medical, Inc, St Paul, Minn), and Medtronic Profile 3D (Medtronic, Minneapolis, Minn) annuloplasty rings with and without the fabric covering were measured with electronic calipers. These rings were compared with a Carpentier-Edwards Physio ring (Edwards Lifesciences) to assess the relative amount of septal-lateral and commissure-commissure dimension change. Average fractional changes $(\% \pm 1$ standard deviation) versus the Physio ring were calculated.

Results: The GeoForm provided the greatest outer septal-lateral reduction relative to Physio ring $(-24 \% \pm 2 \%)$, followed by the IMR ETlogix $(-9 \% \pm 2 \%)$ and Profile 3D $(-8 \% \pm 5 \%)$. The septal-lateral diameter of the Rigid Saddle Annuloplasty Ring was similar to that of the Physio ring $(+1 \% \pm 3 \%)$. Although commissure-commissure outer diameters of the IMR ETlogix, Rigid Saddle Annuloplasty Ring, and Profile 3D were similar to that of the Physio ring $(0 \% \pm 2 \%,+4 \% \pm 3 \%$, and $+3 \% \pm 4 \%$, respectively), the GeoForm had a larger commissurecommissure dimension $(+12 \% \pm 2 \%)$. The inner diameter septal-lateral reductions were even more pronounced.

Conclusions: Relative to the Physio ring, the GeoForm has the most outer and inner septal-lateral reduction but larger commissure-commissure dimension; the IMR ETlogix and Profile 3D provide a moderate degree of septallateral reduction without affecting commissure-commissure dimension, and Rigid Saddle Annuloplasty Ring septal-lateral and commissure-commissure diameters are similar to those of the Physio ring. Knowing the degree of disproportionate septal-lateral downsizing inherent in each ring type will help guide surgical decision making.

(J Thorac Cardiovasc Surg 2010;140:117-21)

\section{Supplemental material is available online.}

Mitral annular septal-lateral (S-L) dilatation causing leaflet malcoaptation is a major contributing factor to the development of ischemic/functional mitral regurgitation (IMR/ FMR) ${ }^{1,2}$ A key goal in the surgical approach to mitral valve

\footnotetext{
From the Department of Cardiothoracic Surgery, ${ }^{\text {a }}$ Stanford University School of Medicine, Stanford, Calif; and the Laboratory of Cardiovascular Physiology and Biophysics, ${ }^{\text {b }}$ Research Institute of the Palo Alto Medical Foundation, Palo Alto, Calif.

Supported by grants HL-29589 and HL-67025 from the National Heart, Lung, and Blood Institute. Dr Bothe was supported by the Deutsche Herzstiftung, Frankfurt, Germany. Dr Swanson was funded by a Western States Affiliate American Heart Association Postdoctoral Fellowship.

Disclosures: D.C. Miller reports consultant fees from St Jude and Medtronic.

Received for publication Sept 5, 2008; revisions received Sept 10, 2009; accepted for publication Oct 14, 2009; available ahead of print Jan 14, 2010.

Address for reprints: D. Craig Miller, MD, Department of Cardiothoracic Surgery, Falk Cardiovascular Research Center, Stanford University School of Medicine, Stanford, CA $94305-5247$ (E-mail: dcm@stanford.edu).

$0022-5223 / \$ 36.00$

Copyright (C) 2010 by The American Association for Thoracic Surgery

doi:10.1016/j.jtcvs.2009.10.033
}

repair for IMR/FMR is to overcome this process by reducing the $\mathrm{S}-\mathrm{L}$ dimension of the annulus. Conventional undersized annuloplasty rings (ARs), however, decrease both $\mathrm{S}-\mathrm{L}$ and commissure-commissure $(\mathrm{C}-\mathrm{C})$ annular dimensions and thus might decrease mitral orifice area excessively and have been associated with high rates of recurrent mitral regurgitation. ${ }^{3}$ Therefore new disease-specific ARs have been designed that disproportionately reduce the mitral annular S-L dimension and therefore avoid the need for aggressive ring "downsizing." ${ }^{,-6}$ Whether and/or how much these new rings reduce $\mathrm{S}-\mathrm{L}$ dimension, however, is proprietary information and debated. The absence of this information hampers optimal surgical decision making as to which ring type to use and might adversely affect outcomes after mitral valve repair for IMR/FMR. ${ }^{7}$ The goal of this study was to assess the amount of disproportionate mitral annular $\mathrm{S}-\mathrm{L}$ reduction inherent in 4 new ARs that have been recently introduced for the surgical treatment of IMR/FMR.

\section{MATERIALS AND METHODS}

One AR of each available size of the Carpentier-Edwards Physio ring, Edwards GeoForm, Edwards IMR ETlogix (all Edwards Lifesciences, 


$$
\begin{aligned}
& \text { Abbreviations and Acronyms } \\
& \begin{array}{ll}
\mathrm{AR} & =\text { annuloplasty ring } \\
\mathrm{C}-\mathrm{C} & =\text { commissure-commissure } \\
\mathrm{IMR} / \mathrm{FMR}= & \text { ischemic/functional } \\
& \text { mitral regurgitation } \\
\mathrm{SD} & =\text { standard deviation } \\
\mathrm{S}-\mathrm{L} & =\text { septal-lateral } \\
\text { 3-D } & =3 \text {-dimensional } \\
\text { 2-D } & =2 \text {-dimensional }
\end{array}
\end{aligned}
$$

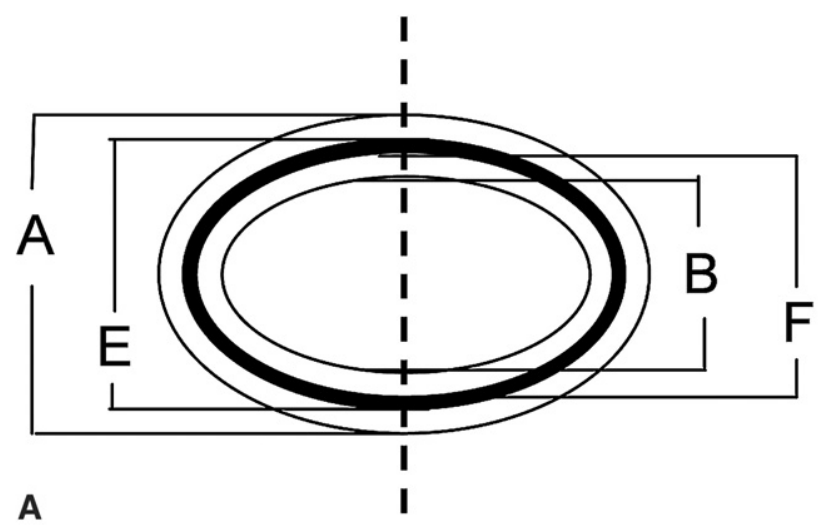

Irvine, Calif), St Jude Medical Rigid Saddle Annuloplasty Ring (RSAR; St Jude Medical, Inc, St Paul, Minn), and Medtronic Profile 3D (Medtronic, Minneapolis, Minn) were provided by the manufacturers. Outer and inner $\mathrm{S}-\mathrm{L}$ and $\mathrm{C}-\mathrm{C}$ diameters of each $\mathrm{AR}$ were measured with an electronic caliper in their preimplanted state (Mitutoyo MIT500-193; Absolute Digimatic Caliper, Mitutoyo Corp, Aurora, Ill).

The resolution of the caliper was $0.01 \mathrm{~mm}$, and the accuracy was $0.04 \mathrm{~mm}$. Dimensions were assessed with and without the fabric sewing cuff. Diameters were labeled from A to $\mathrm{H}$ to facilitate data comparison as follows: A, outer S-L with fabric; B, inner S-L with fabric; C, outer C-C with fabric; D, inner $\mathrm{C}-\mathrm{C}$ with fabric; $\mathrm{E}$, outer $\mathrm{S}-\mathrm{L}$ without fabric; $\mathrm{F}$, inner $\mathrm{S}-\mathrm{L}$ without fabric; $\mathrm{G}$, outer $\mathrm{C}-\mathrm{C}$ without fabric; and $\mathrm{H}$, inner $\mathrm{C}-\mathrm{C}$ without fabric (Figure 1). A Carpentier-Edwards Physio ring was used as a reference standard to assess the relative amount of $\mathrm{S}-\mathrm{L}$ and $\mathrm{C}-\mathrm{C}$ dimension change. The average fractional changes $(\% \pm 1$ standard deviation $[\mathrm{SD}]$ ) in $\mathrm{S}-\mathrm{L}$ and $\mathrm{C}-\mathrm{C}$ diameter versus those of the Physio ring were calculated. Average fractional changes $(\% \pm 1 \mathrm{SD})$ in $\mathrm{S}-\mathrm{L} / \mathrm{C}-\mathrm{C}$ ratio of the respective rings were assessed to assess the amount of disproportionate $\mathrm{S}-\mathrm{L}$ reduction.

The inside orifice area of the fabric-covered rings was assessed from top-view pictures (Figure 2, upper column) to compute 2-dimensional (2-D) projected orifice areas by using Adobe Photoshop CS3 Extended (Adobe Systems, Inc, San Jose, Calif). These 2-D orifice areas were compared with a Carpentier-Edwards Physio ring, and average fractional area changes $(\% \pm 1 \mathrm{SD})$ versus the Physio ring were calculated.

\section{RESULTS}

Figure 2 shows pictures of the ARs studied (all size 30) as viewed from the left atrium to provide a visual comparison of the dimensions, shape, and outer and inner construction of the rings. The upper row shows the rings with the fabric covering (woven polyester for the Physio ring, ETlogix, and Profile 3D; polyester velour for the GeoForm; and polyester double velour that folds on itself to create a suture cuff for the RSAR). The oval shape of the Physio ring, the Dshape of the RSAR, the "dog-bone shape" of the GeoForm, the "heart shape" of the Profile 3D, and the asymmetric shape of the IMR ETlogix with reduced arc in the P3 ring segment can be appreciated. The middle row shows the metal cores of the Physio ring, GeoForm, IMR ETlogix, and Profile 3D with the silicone cuffs. The lower row shows the metal core for all ring types (Elgiloy for Physio ring and titanium alloy for GeoForm, IMR ETlogix, RSAR, and Profile 3D).

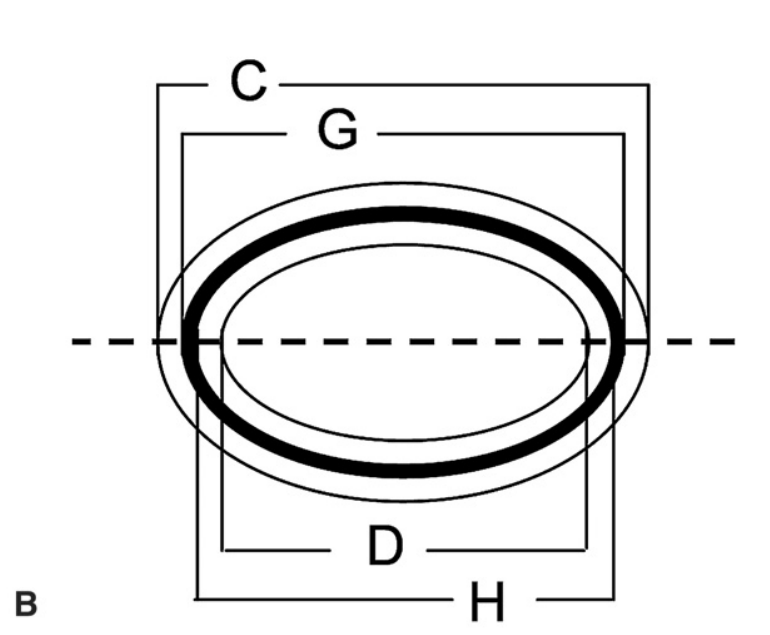

FIGURE 1. Schematic illustrating septal-lateral (A) and commissure-commissure (B) dimensions of the annuloplasty rings measured. (A) $A$, outer S-L diameter with fabric; $B$, inner S-L diameter with fabric; $E$, outer S-L diameter without fabric; $F$, inner S-L diameter without fabric. (B) $C$, outer $\mathrm{C}-\mathrm{C}$ diameter with fabric; $D$, inner $\mathrm{C}-\mathrm{C}$ diameter with fabric; $G$, outer $\mathrm{C}-\mathrm{C}$ diameter without fabric; $H$, inner $\mathrm{C}-\mathrm{C}$ diameter without fabric.

\section{S-L and C-C Dimensions}

Tables E1 and E2 summarize the $\mathrm{S}-\mathrm{L}$ and $\mathrm{C}-\mathrm{C}$ dimensions of all rings in all sizes and their percentage change versus those of the Physio ring with (Table E1) and without (Table E2) the fabric covering. The ring diameters do not correlate with their nominally labeled sizes except for the inner $\mathrm{C}-\mathrm{C}$ diameter of the Physio ring without the fabric covering (H). S-L dimension was largest for the Physio ring and RSAR, smaller for the IMR ETLogix, and smallest for the GeoForm. Note that the outer S-L dimension with fabric (A) of the largest (size 32) GeoForm ring was 19.7 $\mathrm{mm}$, which is smaller than the $\mathrm{S}-\mathrm{L}$ dimension of the smallest available Physio ring (A: $20.4 \mathrm{~mm}$, size 24). Tables E1 and E2 also demonstrate that the percentage change in S-L dimension versus the Physio ring might not only vary depending on the diameter being assessed (inner or outer, with or without cloth; eg, GeoForm, size 26, A: $-22 \%$, B: $-39 \%$ ) but also varies between different ring sizes; for example, 


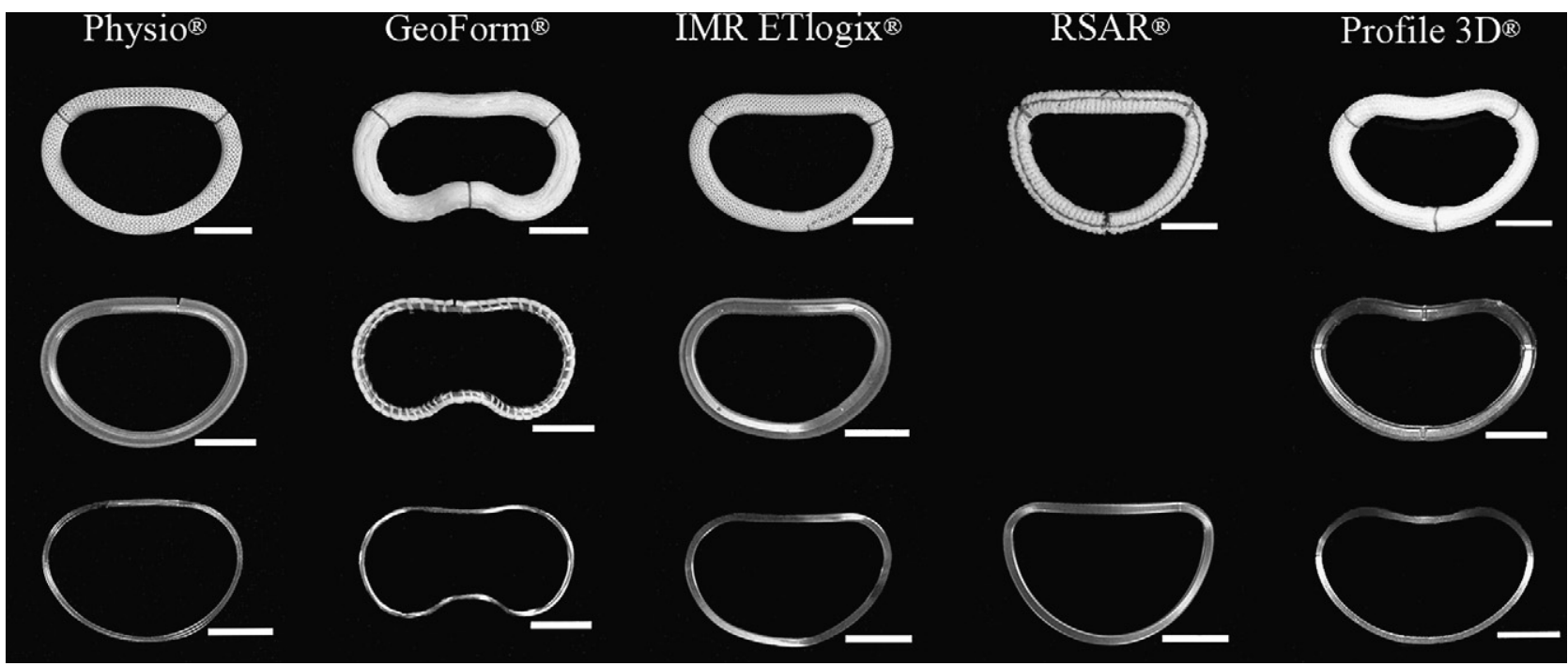

FIGURE 2. Top (left atrial) view of the annuloplasty rings compared (all size 30). The upper row shows the rings with the fabric covering, the middle row shows the rings without the fabric but with the rubber core (not present in RSAR), and the lower row shows just the pure metal ring. The white bar indicates the scale $(10 \mathrm{~mm})$.

the Profile 3D S-L dimension in the smaller sizes has less $\mathrm{S}-\mathrm{L}$ reduction compared with the Physio ring (size 24, A: $+1 \%$ ), whereas the larger Profile 3D sizes provide a greater degree of S-L downsizing (size 40, A:-16\%). Interestingly, the dimensions of the Profile 3D 24 and 26 size rings are almost identical, as are those of the 38 and 40 size rings.

\section{Average Fractional Changes in S-L and C-C Dimensions}

Average fractional changes in $\mathrm{S}-\mathrm{L}$ and $\mathrm{C}-\mathrm{C}$ dimensions assessed with and without the fabric covering versus those of the Physio ring are depicted in Figure 3, $A$ and $B$, respectively. With the fabric covering (Figure 3, $A$ ), the GeoForm provides the greatest $\mathrm{S}-\mathrm{L}$ reduction relative to the Physio ring (A: $-24 \% \pm 2 \%, \mathrm{~B}:-38 \% \pm 2 \%$ ), followed by the IMR ETlogix (A: $-9 \% \pm 2 \%, \mathrm{~B}:-14 \% \pm 2 \%$ ) and Profile $3 \mathrm{D}(\mathrm{A}:-8 \% \pm 5 \%$, B: $-15 \% \pm 3 \%)$. The outer S-L diameter (A) of the RSAR was almost identical to that of the Physio ring (A: $+1 \% \pm 3 \%$ ), whereas the inner diameter (B) was slightly smaller (B: $-6 \% \pm 2 \%$ ). Although the outer $\mathrm{C}-\mathrm{C}$ diameters with fabric $(\mathrm{C})$ of the IMR ETlogix, RSAR, and Profile 3D were similar to that of the Physio ring $(0 \% \pm$ $2 \%,+4 \% \pm 3 \%$, and $+3 \% \pm 4 \%$, respectively), the GeoForm had a larger outer $\mathrm{C}-\mathrm{C}$ dimension $(\mathrm{C}:+12 \% \pm 2 \%)$.

\section{Measured Versus Claimed S- $\mathrm{L}$ and C-C Dimensions}

Tables E3 and E4 show the ring dimensions provided by the manufacturers with and without fabric covering, respectively, along with the differences between these specifications and the dimensions we measured. The outer and inner S-L diameters of the Physio ring and ETLogix with fabric (A and B, respectively), as well as the outer $\mathrm{S}-\mathrm{L}$ diameters of the GeoForm and Profile 3D with fabric covering (A) were not provided by the manufacturers (Table E3). The RSAR was the only ring for which the clinically important outer S-L dimension with fabric covering (A) was provided. The only dimension that was provided by all manufacturers for all ring types was the inner $\mathrm{C}-\mathrm{C}$ diameter without the fabric covering. The average difference between measured diameters and the manufacturers' numbers (measured minus claimed) was $0 \pm 0.9 \mathrm{~mm}$ (range, -2.5 to +2.0 $\mathrm{mm})$.

\section{S-L/C-C Ratios}

The average fractional changes in inner and outer S-L/ $\mathrm{C}-\mathrm{C}$ ratios with and without fabric covering versus the Physio ring are shown in Figure 4. Compared with the Physio ring, the GeoForm had the smallest $\mathrm{S}-\mathrm{L} / \mathrm{C}-\mathrm{C}$ ratios (ie, most disproportionate $\mathrm{S}-\mathrm{L}$ reduction), which ranged from $-29 \%$ $\pm 1 \%(\mathrm{~F} / \mathrm{H})$ to $-23 \% \pm 1 \%(\mathrm{~A} / \mathrm{C})$, followed by the IMR ETlogix (ranging from $-8 \% \pm 1 \%[\mathrm{~F} / \mathrm{H}]$ to $-6 \% \pm 1 \%$ $[\mathrm{E} / \mathrm{G}])$, Profile 3D $(-11 \% \pm 2 \%[\mathrm{~B} / \mathrm{D}]$ to $-8 \% \pm 2 \%$ $[\mathrm{A} / \mathrm{C}])$, and $\operatorname{RSAR}(-5 \% \pm 2 \%[\mathrm{~F} / \mathrm{H}]$ to $-2 \% \pm 1 \%[\mathrm{~A} / \mathrm{C}])$.

\section{Ring Orifice Areas}

The 2-D orifice areas of the respective ARs along with relative fractional changes versus the Physio ring are summarized in Table E5. Compared with the Physio ring, all sizes had smaller orifice areas compared with rings of the same nominal size. Figure 5 depicts average fractional changes in ring orifice area versus the Physio ring. Surprisingly, reduction in orifice area was greatest with the Profile 3D $(-22 \% \pm 8 \%)$ followed by the GeoForm and IMR ETlogix 

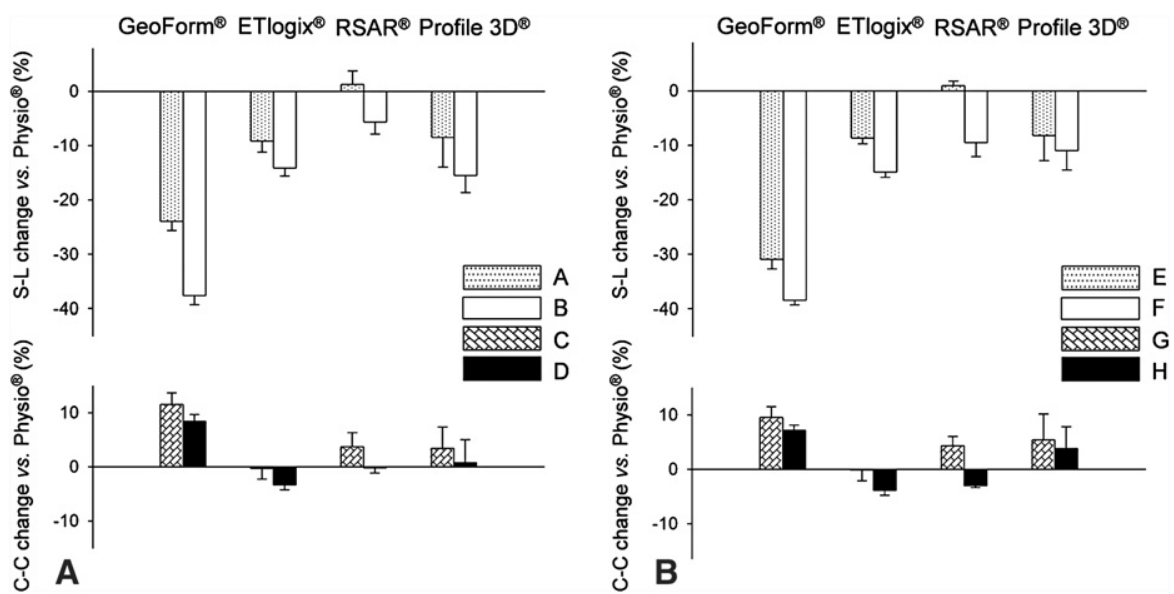

FIGURE 3. Average fractional changes ( $\% \pm 1$ standard deviation) in septal-lateral (S-L) and commissure-commissure (C-C) dimension versus the Carpentier-Edwards Physio ring with fabric covering (A) and without fabric covering (B). (A) A, outer S-L dimension with fabric; $B$, inner S-L dimension with fabric; $C$, outer $\mathrm{C}-\mathrm{C}$ dimension with fabric; and $D$, inner $\mathrm{C}-\mathrm{C}$ dimension with fabric. (B) $E$, outer $\mathrm{S}-\mathrm{L}$ dimension without fabric; $F$, inner $\mathrm{S}-\mathrm{L}$ dimension without fabric; $G$, outer $\mathrm{C}-\mathrm{C}$ dimension without fabric; and $H$, inner $\mathrm{C}-\mathrm{C}$ dimension without fabric.

$(-17 \% \pm 3 \%$ and $-15 \% \pm 2 \%$, respectively), whereas the RSAR's orifice area was only slightly smaller $(-6 \% \pm 2 \%)$.

\section{DISCUSSION}

The main findings of this simple mathematic in vitro exercise were as follows: (1) relative to the Physio ring, the GeoForm reduces annular S-L dimension to the greatest extent while slightly increasing the $\mathrm{C}-\mathrm{C}$ diameter, and thus the GeoForm provides the most disproportionate reduction in mitral annular S-L diameter; (2) the IMR ETlogix and Profile $3 \mathrm{D}$ provide a moderate degree of disproportionate $\mathrm{S}-\mathrm{L}$ reduction; and (3) the $\mathrm{S}-\mathrm{L}$ and $\mathrm{C}-\mathrm{C}$ dimensions of the RSAR and Physio ring are similar.

Knowing the precise dimensions of mitral ARs is important to accurately predict the effects induced by ring implan-

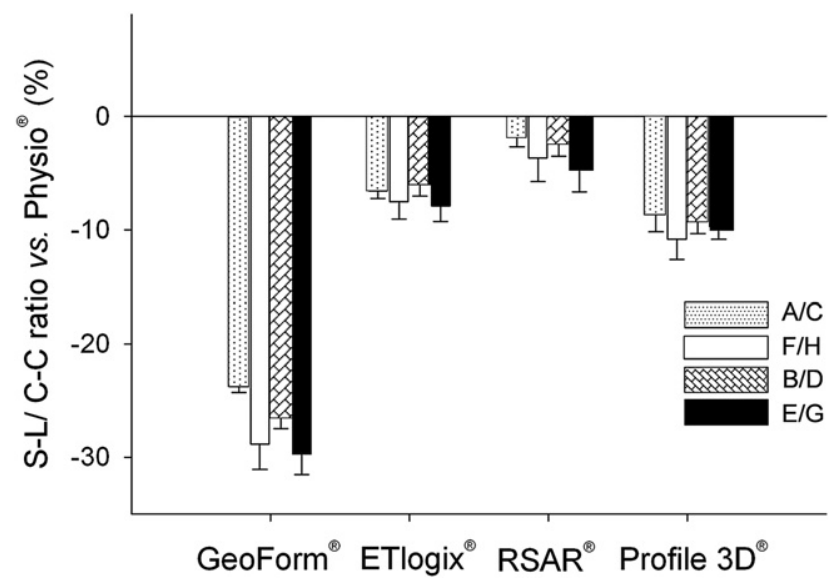

FIGURE 4. Average fractional changes ( $\% \pm 1$ standard deviation) septallateral $(S-L) /$ commissure-commissure $(C-C)$ ratio versus Carpentier-Edwards Physio ring. $A / C$, Outer $\mathrm{S}-\mathrm{L}$ diameter/outer $\mathrm{C}-\mathrm{C}$ diameter with fabric; $B / D$, inner $\mathrm{S}-\mathrm{L} /$ inner $\mathrm{C}-\mathrm{C}$ with fabric; $E / G$, outer $\mathrm{S}-\mathrm{L} /$ outer $\mathrm{C}-\mathrm{C}$ without fabric; $F / H$, inner $\mathrm{S}-\mathrm{L} /$ inner $\mathrm{C}-\mathrm{C}$ without fabric. tation on mitral annular and left ventricular geometry, but unfortunately, such dimensions are proprietary and often incompletely available. Furthermore, such dimensions might not be accurate. ${ }^{8}$ Such a disparity might not only hamper optimal AR sizing but might also affect outcomes after mitral valve repair, as speculated by Kunzelman and colleagues. ${ }^{7}$ Although in our study the average difference between diameters we measured and those claimed by the manufacturers (assessed minus claimed) was trivially small $(0 \pm 0.9 \mathrm{~mm})$, the maximum individual disparity was as high as $-2.5 \mathrm{~mm}$ (for the Profile 3D, size 32, D).

Our measurements demonstrated that the GeoForm provides the greatest amount of disproportionate $\mathrm{S}-\mathrm{L}$ reduction (Figures 3 and 4) of all rings measured. Interestingly, the outer S-L dimension with fabric (A) of the largest available GeoForm (size 32) was $19.7 \mathrm{~mm}$, which is even smaller than the same dimension of the smallest available Physio ring

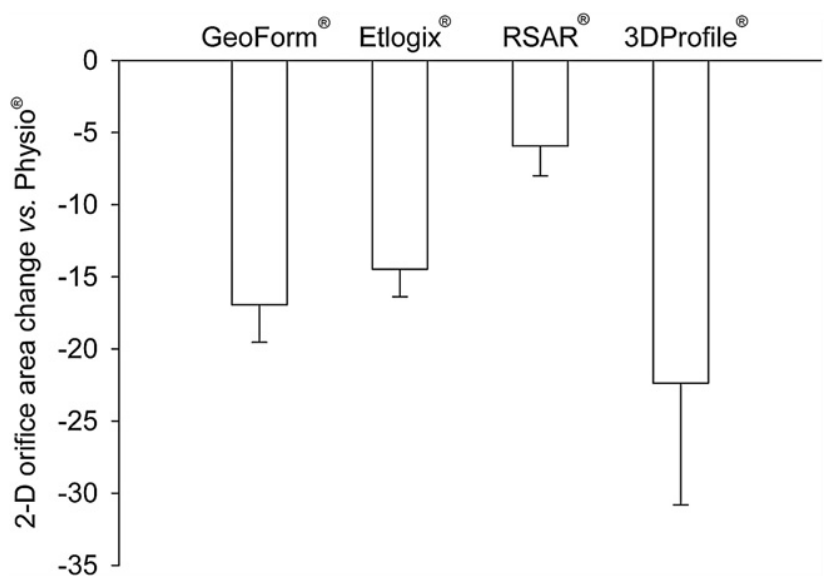

FIGURE 5. Average fractional changes ( $\% \pm 1$ standard deviation) in projected 2-dimensional $(2-D)$ ring orifice area versus the Carpentier-Edwards Physio ring. 
(size 24, A: $20.4 \mathrm{~mm}$ ). Such considerable downsizing of the $\mathrm{S}-\mathrm{L}$ dimension might on one hand recreate the most leaflet coaptation but on the other hand might adversely affect leaflet stresses by deforming the leaflets markedly or possibly impairing left ventricular contractile function, as shown experimentally by Nguyen and associates ${ }^{9}$ from our laboratory, in the left ventricular transmural cardiac and fiber-sheet strain domain. Further studies are needed to investigate whether this extreme amount of S-L annular downsizing is associated with unrecognized side effects.

Our observations spawn several questions. First, when considering ARs intended to disproportionately decrease mitral S-L dimension, to what standard should they be compared? We chose to compare the newly designed rings with the Carpentier-Edwards Physio ring because it is commonly used and purportedly a physiologically shaped AR.

Second, is it sufficient for the surgeon to know only the degree of $\mathrm{S}-\mathrm{L}$ reduction of an $\mathrm{AR}$ as opposed to knowing the degrees of both $\mathrm{S}-\mathrm{L}$ and $\mathrm{C}-\mathrm{C}$ reduction? With respect to the surgical treatment of IMR/FMR, we believe that it is important for the surgeon to gauge the amount of disproportionate $\mathrm{S}-\mathrm{L}$ reduction required to create adequate leaflet coaptation height and area. Therefore it would be better to provide both $\mathrm{S}-\mathrm{L}$ and $\mathrm{C}-\mathrm{C}$ dimensions.

Third, what diameter (outer or inner; with or without fabric) should be chosen to express the actual degree of S- $\mathrm{L}$ reduction? This study revealed that the amount of downsizing varies depending on the diameter chosen. For the GeoForm, for example, $\mathrm{S}-\mathrm{L}$ reduction ranges from $-24 \% \pm 2 \%$ to $-39 \% \pm$ $1 \%$ (outer $\mathrm{S}-\mathrm{L}$ with fabric $[\mathrm{A}]$ vs inner $\mathrm{S}-\mathrm{L}$ without fabric [F]; Figure 3, $A$ and $B$, respectively). Given that the anatomic mitral annulus is sutured to the outer side of the AR, providing a range of S-L reduction that refers to the outer diameter (with and without fabric) probably is the most practical approach.

Fourth, how do the $\mathrm{S}-\mathrm{L}$ and $\mathrm{C}-\mathrm{C}$ dimensions correlate with ring orifice area? Surprisingly, although the GeoForm provides a greater reduction in S-L dimension than the IMR ETlogix, the reduction in orifice area associated with the GeoForm and ETlogix rings are almost the same; indeed, the Profile 3D actually has the smallest ring orifice areas. This reflects the heterogeneity and complexity of these newly designed IMR/FMR ring types and emphasizes the importance of taking all ring specifications into consideration before choosing which one is best for an individual patient.

Fifth, does the 3-dimensional (3-D) shape of an AR affect the postoperative amount of leaflet coaptation? Although it has been shown that the Profile 3D might preserve mitral annular nonplanarity and anterior mitral leaflet curvature, ${ }^{10}$ to date, no experimental studies exist demonstrating the effect of alterations in 3-D AR shape on postoperative coaptation height. Because it is difficult to quantify each ring's unique 3-D shape, we focused on describing the $\mathrm{S}-\mathrm{L}$ and $\mathrm{C}-\mathrm{C}$ diameters and the 2-D projected orifice areas, which can easily be compared between rings. Given the complex design of the new ARs, however, comparison of $\mathrm{S}-\mathrm{L}$ and $\mathrm{C}-\mathrm{C}$ diameters might not be sufficient to accurately predict postoperative valve geometry or its effects on left ventricular geometry. Therefore further experimental and clinical studies are needed to investigate the effects of different 3-D AR shapes on the amount of leaflet coaptation that can be achieved.

Finally, will these complex 3-D shapes effectively prevent late MR recurrence in patients undergoing mitral valve ring annuloplasty for IMR/FMR; that is, does the GeoForm ring effectively counteract ongoing left ventricular remodeling and apical leaflet tethering after annuloplasty for IMR/FMR, or do the RSAR and Profile 3D enhance long-term repair durability by virtue of their 3-D saddle shape? All of these questions point to the need for additional clinical studies.

In summary, relative to the Physio ring, the GeoForm reduces annular $\mathrm{S}-\mathrm{L}$ dimension to the greatest extent while slightly increasing $\mathrm{C}-\mathrm{C}$ diameter, thereby creating the most disproportionate reduction in mitral annular $\mathrm{S}-\mathrm{L}$ diameter. The IMR ETlogix and Profile 3D provide a moderate degree of disproportionate S-L reduction. The RSAR ring's dimensions are similar to those of the Physio ring. Knowing the degree of disproportionate $\mathrm{S}-\mathrm{L}$ downsizing associated with each ring type and size should help guide surgical decision making. Future studies are needed to determine whether any of these new disease-specific designed ARs will be effective in reducing the likelihood of recurrent mitral regurgitation and prompt more left ventricular reverse remodeling after mitral annuloplasty in patients with IMR/FMR.

\section{References}

1. Tibayan FA, Rodriguez F, Langer F, Zasio MK, Bailey L, Liang D, et al. Does septal-lateral annular cinching work for chronic ischemic mitral regurgitation? J Thorac Cardiovasc Surg. 2004;127:654-63.

2. Tibayan FA, Rodriguez F, Zasio MK, Bailey L, Liang D, Daughters GT, et al. Geometric distortions of the mitral valvular-ventricular complex in chronic ischemic mitral regurgitation. Circulation. 2003;108(suppl 1):II116-21.

3. McGee EC, Gillinov AM, Blackstone EH, Rajeswaran J, Cohen G, Najam F, et al Recurrent mitral regurgitation after annuloplasty for functional ischemic mitral regurgitation. J Thorac Cardiovasc Surg. 2004;128:916-24.

4. Maisano F, Redaelli A, Soncini M, Votta E, Arcobasso L, Alfieri O. An annular prosthesis for the treatment of functional mitral regurgitation: finite element model analysis of a dog bone-shaped ring prosthesis. Ann Thorac Surg. 2005; 79:1268-75

5. Votta E, Maisano F, Bolling SF, Alfieri O, Montevecchi FM, Redaelli A. The Geoform disease-specific annuloplasty system: a finite element study. Ann Thorac Surg. 2007;84:92-101.

6. Daimon M, Fukuda S, Adams DH, McCarthy PM, Gillinov AM, Carpentier A, et al. Mitral valve repair with Carpentier-McCarthy-Adams IMR ETlogix annuloplasty ring for ischemic mitral regurgitation: early echocardiographic results from a multi-center study. Circulation. 2006;114(suppl):I588-93.

7. Kunzelman KS, Reimink MS, Cochran RP. Variations in annuloplasty ring and sizer dimensions may alter outcome in mitral valve repair. J Card Surg. 1997; 12:322-9.

8. Cochran RP, Kunzelman KS. Discrepancies between labeled and actual dimensions of prosthetic valves and sizers. J Card Surg. 1996;11:318-25.

9. Nguyen TC, Cheng A, Tibayan FA, Liang D, Daughters GT, Ingels NB Jr, et al. Septal-lateral annnular cinching perturbs basal left ventricular transmural strains. Eur J Cardiothorac Surg. 2007;31:423-9.

10. Ryan LP, Jackson BM, Hamamoto H, Eperjesi TJ, Plappert TJ, St John-Sutton M, et al. The influence of annuloplasty ring geometry on mitral leaflet curvature. Ann Thorac Surg. 2008;86:749-60. 


\begin{tabular}{|c|c|c|c|c|c|c|c|c|c|c|c|c|c|c|c|c|c|c|c|c|}
\hline \multirow{2}{*}{$\begin{array}{c}\text { Ring } \\
\text { size }\end{array}$} & \multicolumn{4}{|c|}{ Physio ring } & \multicolumn{4}{|c|}{ GeoForm } & \multicolumn{4}{|c|}{ IMR ETlogix } & \multicolumn{4}{|c|}{ RSAR } & \multicolumn{4}{|c|}{ Profile 3D } \\
\hline & A & B & C & D & A & B & $\mathrm{C}$ & D & A & B & C & D & A & B & C & D & $\mathbf{A}$ & B & C & D \\
\hline 24 & 20.4 & 15.3 & 27.3 & 22.0 & & & & & $19.0(-7)$ & $13.0(-15)$ & $27.9(+2)$ & $21.7(-2)$ & $21.5(+5)$ & $14.0(-8.5)$ & $29.3(+8)$ & $22.4(+2)$ & $20.6(+1)$ & $13.4(-12)$ & $30.4(+11)$ & $24.0(+9)$ \\
\hline 26 & 21.9 & 16.6 & 29.4 & 24.5 & $17.1(-22)$ & $10.1(-39)$ & $33.7(+15)$ & $26.9(+10)$ & $20.3(-7)$ & $14.0(-16)$ & $30.0(+2)$ & $23.8(-3)$ & $22.3(+2)$ & $15.3(-7.9)$ & $31.3(+6)$ & $24.4(0)$ & $20.4(-7)$ & $14.0(-16)$ & $30.4(+3)$ & $23.7(-3)$ \\
\hline 28 & 23.7 & 17.7 & 32.4 & 26.6 & $18.2(-23)$ & $11.3(-36)$ & $35.8(+10)$ & $29.0(+9)$ & $21.5(-9)$ & $15.2(-14)$ & $32.2(-1)$ & $25.6(-4)$ & $23.6(0)$ & $16.8(-5.1)$ & $33.3(+3)$ & $26.4(-1)$ & $22.7(-4)$ & $15.4(-13)$ & $34.4(+6)$ & $27.8(+5)$ \\
\hline 30 & 25.0 & 18.6 & 34.3 & 28.8 & $18.6(-26)$ & $11.9(-36)$ & $38.2(+11)$ & $31.0(+8)$ & $22.5(-10)$ & $16.5(-11)$ & $33.7(-2)$ & $27.6(-4)$ & $25.5(+2)$ & $18.1(-2.6)$ & $35.5(+3)$ & $28.6(-1)$ & $24.1(-3)$ & $16.5(-11)$ & $36.2(+5)$ & $29.6(+3)$ \\
\hline 32 & 26.2 & 20.6 & 36.3 & 30.8 & $19.7(-25)$ & $12.6(-39)$ & $39.9(+10)$ & $33.0(+7)$ & $23.7(-10)$ & $17.8(-14)$ & $35.8(-1)$ & $29.6(-4)$ & $26.5(+1)$ & $19.5(-5.1)$ & $36.9(+2)$ & $30.6(-1)$ & $23.6(-10)$ & $17.4(-15)$ & $36.9(+2)$ & $29.7(-4)$ \\
\hline 34 & 28.4 & 22.0 & 38.6 & 32.7 & & & & & $24.8(-13)$ & $18.7(-15)$ & $37.7(-2)$ & $31.5(-4)$ & $27.8(-2)$ & $21.0(-4.6)$ & $38.9(+1)$ & $32.6(0)$ & $24.8(-13)$ & $17.8(-19)$ & $38.7(0)$ & $32.2(-2)$ \\
\hline 36 & 29.6 & 23.4 & 40.9 & 34.6 & & & & & & & & & & & & & $25.8(-13)$ & $18.7(-20)$ & $40.6(-1)$ & $33.8(-2)$ \\
\hline 38 & 31.1 & 24.6 & 43.0 & 36.8 & & & & & & & & & & & & & $27.7(-11)$ & $21.1(-14)$ & $44.5(+3)$ & $37.9(+3)$ \\
\hline 40 & 32.9 & 26.3 & 44.8 & 38.6 & & & & & & & & & & & & & $27.5(-16)$ & $21.4(-19)$ & $44.6(-1)$ & $37.9(-2)$ \\
\hline \multirow{2}{*}{\multicolumn{21}{|c|}{$\begin{array}{l}A \text { through } D \text { represent ring dimensions assessed with fabric: } A \text {, outer septal-lateral }(\mathrm{S}-\mathrm{L}) \text { diameter; } B \text {, inner } \mathrm{S}-\mathrm{L} \text { diameter; } C \text {, outer commissure-commissure }(\mathrm{C}-\mathrm{C}) \text { diameter; } D \text {, inner } \mathrm{C}-\mathrm{C} \text { diameter. Values are shown are in millimeters } \\
\text { and values in parentheses indicate the percentage change relative to the Carpentier-Edwards Physio ring. }\end{array}$}} \\
\hline & & & & & & & & & & & & & & & & & & & & \\
\hline \multirow{2}{*}{$\begin{array}{c}\text { Ring } \\
\text { size }\end{array}$} & \multicolumn{4}{|c|}{ Physio ring } & \multicolumn{4}{|c|}{ GeoForm } & \multicolumn{4}{|c|}{ IMR ETlogix } & \multicolumn{4}{|c|}{ RSAR } & \multicolumn{4}{|c|}{ Profile 3D } \\
\hline & $\mathbf{E}$ & $\mathbf{F}$ & G & $\mathbf{H}$ & $\mathbf{E}$ & $\mathbf{F}$ & G & H & $\mathbf{E}$ & $\mathbf{F}$ & G & H & E & $\mathbf{F}$ & G & $\mathrm{H}$ & E & F & G & $\mathrm{H}$ \\
\hline 24 & 18.0 & 16.6 & 25.0 & 23.6 & & & & & $16.5(-8)$ & $14.0(-16)$ & $25.6(+3)$ & $23.0(-2)$ & $18.1(0)$ & $14.4(-13)$ & $26.6(+7)$ & $22.9(-3)$ & $17.7(-2)$ & $15.4(-7)$ & $28.5(+14)$ & $26.0(+10)$ \\
\hline 26 & 19.3 & 18.0 & 27.1 & 25.7 & $13.8(-28)$ & $11.1(-38)$ & $30.3(+12)$ & $27.8(+8)$ & $17.8(-8)$ & $15.0(-16)$ & $27.5(+2)$ & $24.8(-3)$ & $19.5(+1)$ & $15.8(-12)$ & $28.7(+6)$ & $25.0(-3)$ & $17.7(-8)$ & $15.4(-14)$ & $28.4(+5)$ & $26.0(+1)$ \\
\hline 28 & 20.7 & 18.9 & 29.6 & 28.0 & $14.1(-32)$ & $11.4(-40)$ & $32.4(+10)$ & $29.9(+7)$ & $19.0(-8)$ & $16.2(-14)$ & $29.4(-1)$ & $26.7(-4)$ & $21.0(+1)$ & $17.2(-9)$ & $30.8(+4)$ & $27.0(-3)$ & $20.0(-3)$ & $17.7(-6)$ & $32.4(+10)$ & $30.1(+8)$ \\
\hline 30 & 21.8 & 20.2 & 31.5 & 29.9 & $15.0(-31)$ & $12.6(-37)$ & $34.4(+9)$ & $32.0(+7)$ & $20.1(-8)$ & $17.2(-14)$ & $31.3(0)$ & $28.6(-4)$ & $22.3(+2)$ & $18.6(-8)$ & $32.8(+4)$ & $28.9(-3)$ & $21.2(-3)$ & $18.7(-7)$ & $34.4(+9)$ & $32.1(+8)$ \\
\hline 32 & 23.4 & 21.6 & 33.9 & 32.0 & $15.9(-32)$ & $13.3(-39)$ & $36.4(+7)$ & $34.0(+6)$ & $21.2(-10)$ & $18.4(-15)$ & $33.3(-2)$ & $30.7(-4)$ & $23.7(+1)$ & $20.0(-7)$ & $34.9(+3)$ & $31.1(-3)$ & $21.2(-10)$ & $18.9(-12)$ & $34.5(+2)$ & $32.1(0)$ \\
\hline 34 & 24.9 & 22.9 & 35.9 & 34.0 & & & & & $22.3(-10)$ & $19.8(-14)$ & $35.1(-2)$ & $32.5(-5)$ & $24.8(0)$ & $21.2(-8)$ & $36.7(+2)$ & $32.9(-3)$ & $22.1(-11)$ & $19.9(-13)$ & $36.4(+1)$ & $34.0(0)$ \\
\hline 36 & 26.4 & 24.1 & 37.9 & 35.9 & & & & & & & & & & & & & $23.3(-12)$ & $20.8(-14)$ & $38.4(+1)$ & $36.1(+1)$ \\
\hline 38 & 28.1 & 25.5 & 40.0 & 38.0 & & & & & & & & & & & & & $25.4(-9)$ & $23.2(-9)$ & $42.4(+6)$ & $40.2(+6)$ \\
\hline 40 & 29.8 & 27.4 & 42.0 & 39.6 & & & & & & & & & & & & & $25.2(-15)$ & $23.1(-16)$ & $42.3(+1)$ & $40.1(+1)$ \\
\hline
\end{tabular}

$E$ through $F$ represent ring dimensions assessed without fabric: $E$, outer septal-lateral $(\mathrm{S}-\mathrm{L})$ diameter; $F$, inner S-L diameter; $G$, outer commissure-commissure (C-C) diameter; $H$, inner $\mathrm{C}-\mathrm{C}$ diameter. Values shown are in millimeters. Values in parentheses indicate the percentage change relative to the Carpentier-Edwards Physio ring. 


\begin{tabular}{|c|c|c|c|c|c|c|c|c|c|c|c|c|c|c|c|c|c|c|c|c|}
\hline \multirow[b]{2}{*}{$\begin{array}{c}\text { Ring } \\
\text { size }\end{array}$} & \multicolumn{4}{|c|}{ Physio ring } & \multicolumn{4}{|c|}{ GeoForm } & \multicolumn{4}{|c|}{ IMR ETlogix } & \multicolumn{4}{|c|}{ RSAR } & \multicolumn{4}{|c|}{ Profile 3D } \\
\hline & A & B & C & D & A & B & C & D & A & B & C & D & A & B & C & D & A & B & C & D \\
\hline 24 & DNP & DNP & $28.7(-1.4)$ & $22.9(-0.9)$ & & & & & DNP & DNP & $28.2(-0.3)$ & $21.8(-0.1)$ & $21.3(+0.1)$ & $13.6(+0.4)$ & $30.0(-0.7)$ & $22.0(+0.4)$ & DNP & $13.4(0)$ & $30.5(-0.1)$ & $24.2(-0.2)$ \\
\hline 26 & DNP & DNP & $30.7(-1.3)$ & $24.9(-0.4)$ & DNP & $10.3(-0.2)$ & $34.2(-0.5)$ & $26.4(+0.5)$ & DNP & DNP & $30.1(-0.1)$ & $23.7(+0.1)$ & $22.6(-0.2)$ & $15.1(+0.2)$ & $32.0(-0.8)$ & $24.0(+0.4)$ & DNP & $14.5(-0.5)$ & $32.5(-2.1)$ & $26.2(-2.5)$ \\
\hline 28 & DNP & DNP & $32.9(-0.5)$ & $26.9(-0.3)$ & DNP & $11.3(+0.1)$ & $36.2(-0.4)$ & $28.4(+0.6)$ & DNP & DNP & $32.1(+0.1)$ & $25.7(-0.1)$ & $24.3(-0.7)$ & $16.2(+0.6)$ & $34.0(-0.7)$ & $26.0(+0.4)$ & DNP & $15.6(-0.2)$ & $34.5(-0.1)$ & $28.2(-0.4)$ \\
\hline 30 & DNP & DNP & $34.9(-0.6)$ & $28.9(-0.1)$ & DNP & $11.9(-0.1)$ & $38.3(-0.1)$ & $30.5(+0.5)$ & DNP & DNP & $34.0(-0.3)$ & $27.6(0)$ & $25.9(-0.3)$ & $17.9(+0.2)$ & $36.0(-0.5)$ & $28.0(+0.6)$ & DNP & $16.7(-0.2)$ & $36.5(-0.3)$ & $30.2(-0.6)$ \\
\hline 32 & DNP & DNP & $37.1(-0.8)$ & $30.9(-0.1)$ & DNP & $12.6(-0.3)$ & $40.3(-0.4)$ & $32.5(+0.5)$ & DNP & DNP & $35.9(-0.1)$ & $29.5(+0.1)$ & $26.6(-0.1)$ & $19.2(+0.4)$ & $38.0(-1.1)$ & $30.0(+0.6)$ & DNP & $17.8(-0.4)$ & $38.5(-1.6)$ & $32.2(-2.5)$ \\
\hline 34 & DNP & DNP & $39.1(-0.5)$ & $32.9(-0.2)$ & & & & & DNP & DNP & $37.8(-0.1)$ & $31.4(+0.1)$ & $28.5(-0.7)$ & $20.6(+0.4)$ & $40.0(-1.1)$ & $32.0(+0.6)$ & DNP & $18.9(-1.1)$ & $40.5(-1.8)$ & $34.2(-2.0)$ \\
\hline 36 & DNP & DNP & $41.2(-0.4)$ & $34.8(-0.2)$ & & & & & & & & & & & & & DNP & $19.8(-1.1)$ & $42.5(-1.9)$ & $36.2(-2.4)$ \\
\hline 38 & DNP & DNP & $43.2(-0.2)$ & $36.8(0)$ & & & & & & & & & & & & & DNP & $20.9(+0.2)$ & $44.5(0)$ & $38.2(-0.3)$ \\
\hline 40 & DNP & DNP & $45.3(-0.5)$ & $38.7(-0.2)$ & & & & & & & & & & & & & DNP & $22.0(-0.6)$ & $46.5(-1.9)$ & $40.2(-2.3)$ \\
\hline
\end{tabular}

$A$ through $D$ represent ring dimensions provided with fabric: $A$, outer septal-lateral (S-L) diameter; $B$, inner S-L diameter; $C$, outer commissure-commissure (C-C) diameter; $D$, inner C-C diameter. Values shown are in millimeters. Values in parentheses indicate the difference in millimeters between diameters assessed and claimed (assessed minus claimed). $D N P$, Data not provided.

TABLE E4. Annuloplasty ring dimensions without fabric provided by the manufacturers

\begin{tabular}{|c|c|c|c|c|c|c|c|c|c|c|c|c|c|c|c|c|c|c|c|c|}
\hline \multirow[b]{2}{*}{ Ring size } & \multicolumn{4}{|c|}{ Physio ring } & \multicolumn{4}{|c|}{ GeoForm } & \multicolumn{4}{|c|}{ IMR ETlogix } & \multicolumn{4}{|c|}{ RSAR } & \multicolumn{4}{|c|}{ Profile 3D } \\
\hline & E & $\mathbf{F}$ & G & H & E & $\mathbf{F}$ & G & H & E & $\mathbf{F}$ & G & H & $\mathbf{E}$ & $\mathbf{F}$ & G & H & E & F & G & H \\
\hline 24 & DNP & DNP & DNP & $24.0(-0.4)$ & & & & & DNP & $13.8(0.2)$ & DNP & $23.0(0)$ & DNP & DNP & DNP & $23.0(-0.1)$ & DNP & DNP & DNP & DNP \\
\hline 26 & DNP & DNP & DNP & $26.0(-0.3)$ & DNP & DNP & DNP & $27.9(-0.1)$ & DNP & $15.0(0)$ & DNP & $24.9(-0.1)$ & DNP & DNP & DNP & $25.0(0)$ & DNP & DNP & DNP & DNP \\
\hline 28 & DNP & DNP & DNP & $28.0(0)$ & DNP & DNP & DNP & $30.0(-0.1)$ & DNP & $16.1(0.1)$ & DNP & $26.8(-0.1)$ & DNP & DNP & DNP & $27.0(0)$ & DNP & DNP & DNP & DNP \\
\hline 30 & DNP & DNP & DNP & $30.0(-0.1)$ & DNP & DNP & DNP & $32.0(0)$ & DNP & $17.3(-0.1)$ & DNP & $28.8(-0.2)$ & DNP & DNP & DNP & $29.0(-0.1)$ & DNP & DNP & DNP & DNP \\
\hline 32 & DNP & DNP & DNP & $32.0(0)$ & DNP & DNP & DNP & $34.0(0)$ & DNP & $18.4(0)$ & DNP & $30.7(0)$ & DNP & DNP & DNP & 31. $(+0.1)$ & DNP & DNP & DNP & DNP \\
\hline 34 & DNP & DNP & DNP & $34.0(0)$ & & & & & DNP & $19.6(0.1)$ & DNP & $32.6(-0.1)$ & DNP & DNP & DNP & $33.0(-0.1)$ & DNP & DNP & DNP & DNP \\
\hline 36 & DNP & DNP & DNP & $36.0(-0.1)$ & & & & & & & & & & & & & DNP & DNP & DNP & DNP \\
\hline 38 & DNP & DNP & DNP & $38.0(0)$ & & & & & & & & & & & & & DNP & DNP & DNP & DNP \\
\hline 40 & DNP & DNP & DNP & $40.0(-0.4)$ & & & & & & & & & & & & & DNP & DNP & DNP & DNP \\
\hline
\end{tabular}

limeters. Values in parentheses indicate the difference in millimeters between diameters assessed and claimed (assessed minus claimed). DNP, Data not provided.

(4) 
TABLE E5. Measured 2-dimensional projected orifice areas of annuloplasty rings

\begin{tabular}{lccccc}
\hline \multirow{2}{*}{$\begin{array}{c}\text { Ring } \\
\text { size }\end{array}$} & \multicolumn{5}{c}{ Orifice areas $\left(\mathbf{m m}^{2}\right)$} \\
\cline { 2 - 6 } & Physio ring & GeoForm & ETlogix & RSAR & Profile 3D \\
\hline 24 & 263 & & $225(-14)$ & $241(-8)$ & $237(-10)$ \\
26 & 311 & $257(-17)$ & $259(-17)$ & $290(-7)$ & $221(-29)$ \\
28 & 358 & $311(-13)$ & $317(-11)$ & $350(-2)$ & $308(-14)$ \\
30 & 426 & $346(-19)$ & $361(-15)$ & $403(-5)$ & $346(-19)$ \\
32 & 493 & $402(-18)$ & $428(-13)$ & $461(-6)$ & $353(-28)$ \\
34 & 576 & & $485(-16)$ & $539(-6)$ & $364(-37)$ \\
36 & 630 & & & & $481(-24)$ \\
38 & 726 & & & & $607(-16)$ \\
40 & 807 & & & $609(-25)$ \\
\hline
\end{tabular}

change relative to the Carpentier-Edwards Physio ring. 